\title{
Presentación de Infancia/Dictadura. Testigos y actores (1973-1990)
}

\section{Book Presentation: Infancia/Dictadura. Testigos y actores (1973-1990)}

\author{
Ana Victoria García Tapia \\ Universidad Nacional Autónoma de México \\ Facultad de Filosofía y Letras \\ anavictoriana_@hotmail.com
}

El 17 de julio de 2019, en el teatro El Milagro se presentó el libro Infancia/Dictadura. Testigos y actores (1973-1990), de la chilena Patricia Castillo Gallardo, doctora en psicología que ha trabajado a profundidad el tema de la infancia en tiempos de dictadura.

La presentación se hizo como parte de las actividades del taller Transmisiones, acompañamiento, investigación y prácticas narrativas para hilvanar nuestro tiempo, el cual tiene lugar en este teatro dos veces por mes. Está dirigido principalmente a la comunidad teatral y artística interesada en la promoción y defensa de los derechos humanos, así como a la comunidad de defensoras y defensores de estos en general. El proyecto es coordinado por Rafael Mondragón, Laura García y Rita Canto. ${ }^{1}$

El libro aborda el tema de la infancia en el ambiente de violencia política durante la dictadura chilena de 1973 a 1990. Es un estudio sobre lo que significó este contexto para los niños que lo vivieron y también una recopilación de testimonios de primera mano, de sus vivencias, contadas por ellos mismos. En sus páginas encontramos cartas, dibujos, fotografías, colecciones, etc., pues uno de los objetivos de la investigación es darles su lugar en la historia a los más pequeños y nombrarlos tanto como testigos y como actores en este proceso político tan complicado que vivió Chile. Gracias a esta investigación,

1 Para más información sobre este proyecto, consúltese <https://elmilagro.org. $\mathrm{mx} /$ transmisiones/>. 
con estos objetos se conformó el primer archivo histórico de producciones infantiles en Chile, que será resguardado en el Museo de la Memoria y los Derechos Humanos en Santiago.

La presentación estuvo a cargo de Fátima Moneta, psicóloga feminista cuyo trabajo se enfoca en mejorar las condiciones de salud mental de mujeres y niñas; Daniela Rea, escritora y periodista que ha trabajado temas como migración, derechos humanos, militarización y maternidad; y Áurea Xaydé Esquivel, académica dedicada a la investigación sobre literatura infantil, juvenil y narrativa gráfica. Moderaron Rita Canto y Rafael Mondragón, además, de contar con la presencia de la autora.

Las tres presentadoras hicieron reflexiones desde sus respectivos campos de estudio sobre la infancia, la militarización, la migración y el poder político de los niños. Fátima comentó cómo en estos procesos se tiende a ignorar a los niños y las repercusiones y cuestionamientos que causan en ellos: "Tenemos que prestar atención a cómo viven ellos estos procesos, a cómo los estamos escuchando porque ¿qué hacen ellos con todo lo no dicho?" Siguiendo con la idea, Daniela Rea preguntó: “¿Cómo aprendemos a escucharlos sin domesticar sus relatos, sin quitarles su rebeldía?, ¿cómo escuchamos en cuanto al dolor?, y ¿cómo lo hacemos sin caer en clichés?” No hubo una respuesta clara; sin embargo, señalaron que Infancia/Dictadura... es un buen punto de partida para empezar a resolverlas.

Áurea habló de la importancia de esta escucha, y dijo "Los niños tienen poder político, pues ellos ante todo son cuerpo, son presente y aunque los silenciamos, siempre han encontrado la manera de decirnos lo que sienten, de demostrarlo. Hay que prestar más atención a cómo lo hacen”.

Las presentadoras concordaron en que la investigación de Patricia demostró la importancia del lugar de los niños como actores, testigos y sujetos políticos en todo proceso social. Escucharlos es algo necesario y sus participaciones no pueden ser medidas desde los parámetros adultos sino desde los propios de la infancia, porque no es que los niños no entiendan, sino que lo hacen de una forma distinta, desde otro punto de vista, con igual importancia que el adulto.

También trataron el tema de la vigencia que tienen las reflexiones en esta investigación, porque a pesar de que en el libro se aborda el pasado (la dictadura chilena), hoy seguimos enfrentando circunstancias de gran violencia política en Latinoamérica y más que nunca los niños son víctimas de ellas. Se habló de la situación que se ha producido en México, a raíz de la llamada 
"guerra contra el narco", y de la crisis que vive Centroamérica ante las tremendas olas de migración de los últimos años en las que viaja una alarmante cantidad de niños sin acompañantes.

Los niños siguen enfrentando la violencia del Estado, las desapariciones, el desplazamiento forzado que, se aclaró, son situaciones distintas a una dictadura, pero que también son casos en los que se invisibiliza su participación, así como sus cuestionamientos y las preguntas que surgen ante tales circunstancias. Sobre esto, la autora se unió con una reflexión:

Me pregunto si algún día nos hará gracia que nos digan que los adultos decimos tonteras. Porque en verdad las decimos. Los adultos hacen lo que pueden con las palabras que tienen para explicar cosas innombrables, impensables, para acercarlas al mundo infantil, que rápidamente encuentra su sinsentido. Pues ¿cómo haces que tenga sentido una desaparición o un asesinato? ¿Cómo haces que tenga sentido una dictadura?

Por último, se abrió un espacio para preguntas y aportaciones del público. Preguntaron ¿cómo acercar estos temas a los niños, tanto en el aula como en casa? Y, así como hicieron las presentadoras, relacionaron el tema con el contexto mexicano. Se habló de los niños en el movimiento zapatista y cómo han vivido este proceso, y también de los niños que viven en las zonas con mayor presencia militar en el país.

También participó un exiliado chileno - niño al inicio de la dictadura en su país - que compartió su experiencia y habló de las dos formas de ser un "niño de la dictadura", vivirla en el exilio o en tu país. Remarcó las diferencias entre estas situaciones pero que, finalmente, las ambas impactan y transforman la infancia.

\section{Ana Victoria García Tapia}

Es estudiante de la licenciatura en Lengua y Literaturas Hispánicas en la Facultad de Filosofía y Letras de la Universidad Nacional Autónoma de México. 